\title{
SILVA, Marta Regina Paulo da; MAFRA, Jason Ferreira (org.). Paulo Freire e a Educação das Crianças. São Paulo: BT Acadêmica, 2020.
}

\author{
(1) Nayane Ferreira \\ Doutoranda em Educação \\ Universidade Nove de Julho - UNINOVE. \\ São Paulo, SP - Brasil. \\ nayaneof@gmail.com \\ Maurício Silva \\ Doutor \\ Universidade Nove de Julho - UNINOVE \\ São Paulo, SP - Brasil \\ maurisil@gmail.com
}

Para citar- (ABNT NBR 6023:2018)

Paulo Freire é conhecido internacionalmente por sua dedicação e preocupação com a alfabetização de adultos, além, obviamente, de sua luta por uma educação libertadora, dialógica e contra a violência dos opressores (FREIRE, 2010). Por isso, o livro aqui resenhado revela-se inovador, na medida em que nos oferece um olhar da pedagogia freiriana voltada à educação para crianças. Além disso, como evidenciam os organizadores do livro, Marta Regina Paulo da Silva e Jason Ferreira Mafra, vivemos um período de opressão, um período em que as forças mais conservadoras estão no poder e buscam, cada vez mais, “destruir políticas públicas e conquistas sociais históricas asseguradas a partir das longas lutas do povo brasileiro" (SILVA e MAFRA, 2020, p. 11). Portanto, escrever sobre Paulo Freire e defender o seu legado é também uma forma de resistência política.

O livro reúne nove textos que trazem diferentes perspectivas a respeito das contribuições de Paulo Freire à educação infantil. Seu Prefácio, escrito por Balduíno Antonio Andreola, professor do Programa de Pós-Graduação em Educação do Centro Universitário La Salle, assinala que Freire se preocupou em alfabetizar uma "multidão de mulheres e de homens no Brasil, às quais e aos quais tinha sido cruelmente negado, pelas situações sociais de pobreza extrema, de discriminação e muitas formas de exclusão, o direito de viver sua 
infância" (SILVA e MAFRA, 2020, p. 17); nesse sentido, preocupou-se também com a infância, principalmente com a infância negada e que, de certa forma, pode ser resgatada. Este livro, diz-nos o prefaciador, oportuniza um (re)encontro com o olhar respeitoso e amoroso de Paulo Freire.

O primeiro capítulo, "O Menino Conectivo: a infância como ontologia do ser social em Paulo Freire", escrito por Jason Ferreira Mafra, nos proporciona um encontro com o "menino conectivo" que Paulo Freire foi, como definido por ele mesmo. Tomando como base sua experiência enquanto criança no bairro de Jaboatão, Recife, em que vivia entre os meninos da classe média e os meninos camponeses, Freire definia-se como um "menino conectivo", fundindo duas ideias: a conectividade e a infância. Mafra nos lembra que o menino conectivo sempre teve muito cuidado com suas palavras, portanto, ao escolher estes termos para reportar-se a si mesmo, estava chamando atenção para algo carregado de sentido.

Freire, enquanto "menino conectivo" carrega consigo a ambiguidade de ser, ao mesmo tempo, criança e adulto, resultante de dois contraditórios: "Se, para falar de temas de sua vida adulta recorre à sua meninice, a narrativa dialética de Freire, ao falar da infância, obriga-o também a politizá-la” (p. 48). Talvez por isso, tomando as considerações finais desse capítulo, pela maneira como compreendia a si e ao mundo, a liberdade encontrada em Freire, menino em sua dimensão individual, tem o seu equivalente, enquanto adulto, na dimensão coletiva, por meio de seu projeto de libertação dos oprimidos.

No capítulo seguinte, "Crianças e Infâncias em Paulo Freire”, Marta Regina Paulo da Silva e Edson Fasano compartilham os resultados de uma pesquisa realizada entre 2004 e 2013, pelo Grupo de Estudos e Pesquisas Paulo Freire (GEPF), sobre a perspectiva de uma Pedagogia da Infância Oprimida. Os autores consideram a infância duplamente oprimida: a infância cronológica, quando a criança é oprimida pelo mundo adulto e a infância como condição da existência humana, oprimida pelos desafios da vida humana.

Silva e Fasano, assim como Mafra, apontam para o momento de retrocesso histórico que o Brasil tem vivido e destacam que, desde o período da colonização brasileira, os dias nunca foram fáceis para os oprimidos e as oprimidas de nosso país, mas o discurso demagógico e moralista difundido nos últimos anos passou a atribuir às teorias de Paulo Freire os baixos resultados obtidos nos exames de avaliações externas da educação brasileira, isso porque Freire defendia uma educação voltada à conscientização e à humanização. Já as atuais políticas educacionais estão voltadas à viabilização do capital, na formação de mão de obra para o mercado de trabalho. 
Para os autores, Freire não se preocupava apenas com a educação dos adultos, pois possuía um plano maior de denúncia das relações autoritárias, antidialógicas e opressoras, às quais meninos e meninas, homens e mulheres estão submetidos. Ressaltam também que em Pedagogia do Oprimido o autor faz referências explícitas às crianças ao analisar a "invasão cultural" que tem por objetivo conquistar, dominar e silenciar as pessoas, o que acontece com as vozes negadas e os corpos silenciados das crianças. Por fim, destacam que Freire defende o rompimento deste silenciamento e a construção de uma ação dialógica, inclusive com as crianças, reconhecendo-as como seres históricos, capazes de lerem o mundo e dizerem suas palavras.

Em "Paulo Freire e a (sua) Infância Educadora", Walter Omar Kohan apresenta uma foto datada de 1963 em que Paulo Freire está apontando para as sílabas da palavra tijolo com uma mão, enquanto segura sua filha com a outra, demonstrando muita ternura. Segundo Kohan, "o homem, negro, robusto, sorridente, mostra a mesma firmeza e entusiasmo para se alfabetizar que para segurar sua filha" (SILVA e MAFRA, 2020, p. 85). A infância cronológica de Freire e a maneira como foi alfabetizado por seus pais marcou profundamente suas ideias educacionais, pois não foi alfabetizado com cartilhas, mas com as palavras de seu mundo. O que chama a atenção de Kohan, e também a nossa, com a leitura deste livro, é que nosso Patrono da Educação não perdeu a meninice com o passar dos anos, já que manteve em si a curiosidade, a inquietação e a criatividade do menino que um dia foi.

O quarto capítulo, "Paulo Freire e a Infância no MST", aborda as contribuições do pensador para a educação no Movimento dos Trabalhadores Sem Terra e de como elas influenciam a maneira de pensar a educação das crianças "Sem Terrinha". Seus autores, Edna Araújo Rodrigues Rosseto e Fábio Accardo de Freitas, fazem uma breve retomada histórica da Educação Popular no Brasil, da Primeira República aos movimentos de cultura popular na década de 1960, quando Paulo Freire passa a discutir a educação como um processo de conscientização e formação humana das classes populares.

A Pedagogia do Movimento, sistematizada por Roseli Caldart (2012), foi fortemente influenciada pela teoria pedagógica de Paulo Freire, principalmente no que diz respeito à superação do desafio do analfabetismo nos acampamentos e assentamentos, possuindo cinco matrizes principais: "a luta social, a organização coletiva, o trabalho na terra, a cultura e a história" (SILVA e MAFRA, 2020, p. 115). Nela defende-se que os movimentos sociais devem funcionar como espaço e princípio educativo na formação dos sujeitos sociais coletivos. Os "Sem Terrinha" fortalecem os coletivos infantis, a luta e pertencimento ao movimento, incluindo as crianças no projeto de sociedade e reconhecendo-as em suas 
dimensões revolucionária de classe, reinterpretando e modificando as experiências de Educação Popular defendidas por Freire.

Também no quinto capítulo será reforçada a concepção de criança enquanto sujeito e, não, objeto partindo dos princípios de educação segundo Freire. O Capítulo denominado "Paulo Freire e as crianças: reflexões e olhares sobre a educação da infância", escrito por Franciele Clara Peloso e Ercília Maria Teixeira Angeli de Paula, destaca as aproximações encontradas entre os pressupostos freirianos e a Educação das Infâncias. As autoras observaram que, no que diz respeito às crianças, os textos abordam principalmente as questões relacionadas ao acesso, à permanência e a participação das crianças das classes populares na escola, bem como a qualidade desta educação.

Os livros analisados pelas autoras foram: A Educação na Cidade (2006), Pedagogia da Esperança: em reencontro com a Pedagogia do Oprimido (1992), Política e Educação (1993), Professora Sim, Tia Não: cartas a quem ousa ensinar (1993) e Cartas a Cristina (1994). Neles, as autoras enfatizam discussões de Freire a respeito da avaliação do saber dos meninos e meninas utilizada pela escola, a qual, muitas vezes, desconsideram as experiências trazidas pelas crianças, além de aspectos relativos à participação efetiva das crianças nas discussões político-pedagógicas da escola e à importância de se ensinar tolerância e democracia desde cedo. Por fim, defendem que, ainda que não cite especificamente as crianças em alguns momentos, Freire refere-se a um projeto amplo de humanização, sendo as crianças parte deste grupo.

O capítulo "Os Círculos de Cultura na Educação Infantil”, escrito por Renata Fernandes Borrozzino Marques e Marta Regina Paulo da Silva, traz uma rica experiência dos Círculos de Cultura realizados com crianças. O círculo de cultura consiste em proporcionar espaços para o diálogo, para uma interação que visa compreender e superar os impasses da sociedade em que vivemos.

Marques relata sua experiência enquanto docente de uma turma composta por vinte e três crianças, de quatro e cinco anos de idade, na qual observou que as questões referentes às opressões e relações de gênero eram recorrentes, motivo pelo qual esse assunto foi tomado como tema gerador da experiência. Durante a pesquisa, pode-se constatar que, muitas vezes, as crianças reproduziam aquilo que ouviam dos adultos, porém também houve casos de crianças que transgrediram essas barreiras e começaram a repensar tais crenças. As autoras finalizam reforçando o papel da escola como espaço para a convivência com a diferença, "local de encontro e de confronto" (SILVA e MAFRA, 2020, p. 165), e os círculos de cultura como espaço privilegiado para a prática pedagógica marcada pelo diálogo e pela amorosidade. 
Em "Entre uma escuta atenta e um olhar afetuoso: autismo e escolarização", Régia Vidal dos Santos e Eunice Macedo proporcionam um diálogo entre a concepção de escola concebida por Paulo Freire e a inclusão das crianças com autismo nesse universo. As autoras começam por denunciar os discursos carregados de estereótipos e preconceitos com relação a essas crianças, assim como o impacto desse olhar nos "encontros e aprendizagens das crianças com e sem autismo" (SILVA e MAFRA, 2020, p. 175), e ressaltam que, embora não tenha falado sobre as crianças com autismo, Freire sempre demonstrou profunda preocupação com os problemas de desigualdade, marginalização e sofrimento humano. Assim como se pode ler em outros capítulos, as autoras reforçam o projeto amplo de humanização do pensador; desse modo, suas discussões cabem também nessa questão.

Ao reconhecer a necessidade de se (re)pensar o lugar que essas crianças ocupam nas escolas, Santos e Macedo lembram que, já na década de 1980, Freire e Shor (Medo e ousadia) alertavam para a necessidade, em qualquer transformação social, de estarmos convencidos da necessidade dessa mudança e de nossa responsabilidade por ela. Portanto, finalizam as autoras, a mudança deve começar por meio de um olhar cuidadoso, do diálogo em torno da compreensão para com esses meninos e meninas.

“Auto(trans)formação permanente com professoras(es) e o esperançar 'em um mundo mais bonito', em que todas e todos 'possam rir'” faz-nos um convite para que não deixemos nossos "meninos e meninas" morrerem, e não apenas no que diz respeito às crianças com as quais cruzamos diariamente, mas também à criança que fomos e devemos manter viva. Juliana Goelzer e Celso Ilgo Henz, seu autores, retomam uma carta escrita por Freire a Loris Malaguzzi, educador italiano, em que ressalta a responsabilidade de cada um na transformação do mundo em um lugar mais bonito e na preservação da voz dos meninos e meninas que estão crescendo.

No últimos capítulo, "Pedagogia Dialógica para uma Educação Emancipadora na Infância”, Ligia de Carvalho Abões Vercelli e Roberta Stangherlim apresentam algumas reflexões a respeito do conceito de dialogicidade presente na teoria de educação libertadora de Paulo Freire e da importância dos espaços de formação continuada de professoras e professores para a consolidação da concepção de que educadores e educandos são detentores de saberes diversos, não hierarquizados, e que, juntos, podem problematizar e ressignificar a realidade em que estão inseridos. Por fim, destacam a importância do conhecimento como instrumento de emancipação e a escola como o lugar de sua produção.

Este livro convida-nos a (re)descobrir Paulo Freire e refletirmos de que maneira sua trajetória nos ajuda a pensar a educação das crianças. Além disso, percorrendo suas páginas, 
somos constantemente provocados e convidados a perceber as meninas e os meninos como sujeitos de direitos e parceiros na nossa caminhada por uma sociedade mais justa.

\section{Referências}

CALDART, Roseli Salete. Pedagogia do Movimento Sem Terra. São Paulo: Expressão Popular, 2012.

FREIRE, Paulo. Pedagogia do Oprimido. Rio de Janeiro: Paz e Terra, 2010.

SILVA, Marta Regina Paulo da; MAFRA, Jason Ferreira (org.). Paulo Freire e a Educação das Crianças. São Paulo: BT Acadêmica, 2020. 